\title{
Competency Based Medical Education and its Application in Biochemistry
}

\author{
Shiba Ansari', Sneha Kumari²
}

${ }^{1}$ Assistant Professor, Department of Biochemistry, North Delhi Municipal Corporation \& Hindu Rao Hospital, Delhi. ${ }^{2}$ Assistant Professor, Department of Community Medicine, North Delhi Municipal Corporation \& Hindu Rao Hospital, Delhi. DOI: https://doi.org/10.24321/2455.9199.201906

\section{I $\quad \mathbf{N} \quad \mathbf{F} \quad \mathbf{O}$}

\section{Corresponding Author:}

Sneha Kumari, Department of Community Medicine, North Delhi Municipal Corporation \& Hindu Rao Hospital, Delhi.

E-mail Id:

sneharanjan811@gmail.com

\section{Orcid Id:}

https://orcid.org/0000-0003-2876-8997

How to cite this article:

Ansari S, Kumari S. Competency Based Medical Education and its Application in Biochemistry Competency Based Medical Education and its Application in Biochemistry. Int J HealthCare Edu \& Med Inform 2019; 6(2): 7-9.

Date of Submission: 2019-08-26

Date of Acceptance: 2019-09-25

\section{$\begin{array}{llllllll}\mathbf{A} & \mathbf{B} & \mathbf{S} & \mathbf{T} & \mathbf{R} & \mathbf{A} & \mathbf{C} & \mathbf{T}\end{array}$}

Healthcare profession educators have been pioneering for curriculum development from time to time. One of the innovation proposed in medical graduate curriculum across the globe is Competency Based Medical Education (CBME). Recently, Medical Council of India (MCl) has described the basic competencies for the Indian Medical Graduate (IMG) including a module on attitude, ethics and communication as well. The implementation of the competency based approach necessitates its understanding in the first place. This article gives a brief overview of CBME along with a rationale for its adoption. It mainly focuses on how CBME can be implemented in the context of basic sciences, particularly biochemistry.

Keywords: CBME (Competency Based Medical Education), IMG (Indian Medical Graduate), Integration, ECE (Early Clinical Exposure)

\section{Introduction}

The Medical Education System (MES) is responsible for preparing medical graduates to participate in the health care of society. It is of paramount importance that MES must work to ensure that every graduate is competent to provide the improved quality of medical care and fulfill the health needs of the society.

The current undergraduate medical education is of fixed time duration with a traditional discipline based curriculum. It is subject centered and hierarchical teacher centered with prime focus on acquisition of knowledge. The assessment is summative and focused mainly on knowledge rather than skills. ${ }^{1}$ The result is variability in graduate abilities after medical training. Also, there is deficit of soft skills pertaining to communication, attitude, doctor-patient relationship, ethics and professionalism.

\section{Competency Based Medical Education}

Competency based medical education has been suggested to address the shortcomings of current approaches to training. Competency refers to observable ability of health professional integrating multiple components such as knowledge, skills, values and attitudes. Since CBME is centered on addressing the health system needs of the society, it offers a rational approach to ensure development of competent graduates. This would effectively reinforce social accountability of MES to meet health needs of population.

CBME is an outcome based approach to the design, implementation, assessment and evaluation of medical education programme, using an organizing framework of competencies. ${ }^{2}$ In CBME, the competencies are predetermined based on the health needs of the society i.e. the 
outcomes of training are identified based on societal needs. The medical graduate must attain the defined competencies by the end of the curriculum. Each student might take different time to attain a particular competency. Thus, CBME curriculum is of variable duration with a defined outcome; as opposed to the traditional MES of fixed duration and variable outcome. The teaching-learning and assessment methods in CBME are predominantly skill based rather than being knowledge based. Integration of various subjects to attain a particular competency is a key component of CBME.

Medical Council of India ( $\mathrm{MCl}$ ) has suggested that competency based learning should be implemented in all medical colleges across the country. The defined roles of Indian Medical Graduate (IMG) are that of a clinician, a leader, a communicator, a life-long learner and a professional.CBME is aimed to ensure fulfillment of all requisite roles of IMG. ${ }^{3}$

\section{Developing a Competency Based Curriculum for Biochemistry}

Biochemistry is one of the fundamental subjects in medical curriculum. The comprehension of biochemistry is often considered to be indistinct by medical students, may be due to complex chemical structures and intricate metabolic cycles. Some students fail to realize importance of biochemistry in first year of curriculum and do not devote sufficient time to its learning. Experts emphasize importance of understanding the underlying principles and biochemical aspects, which if not learnt would lead to fragmented knowledge on applied clinical aspects. The knowledge of biochemistry is essential in context of disease or medical problem to facilitate their diagnosis and treatment. However, the current teaching-learning methods need to be improved so as to focus on clinically relevant topics and integrate with clinical subjects. ${ }^{4}$ The restructured model of biochemistry curriculum as per CBME offers a promising approach in this regard. Inclusion of more volume of applied biochemistry and its integration with clinical science will be instrumental in making biochemistry interesting and meaningful subject in medical curriculum.

Some of the competencies suggested for undergraduate medical student in biochemistry are summarized as:

- Be able to interpret laboratory results of enzyme activities and describe clinical importance of various serum enzymes as markers of pathological conditions.

- Be able to discuss the regulation, function and integration of carbohydrate, lipid and protein metabolism along with associated disorders.

- Be able to interpret results of various lab analytes associated with disorders of carbohydrate, lipid and protein metabolism.

- Be able to discuss digestion, absorption and importance of nutrients and disorders associated with nutrition like PEM (Protein Energy Malnutrition) and obesity.

- Be able to describe biochemical role of vitamins and minerals in the body and explain the manifestations of their deficiency and toxicity.

- Be able to describe the processes involved in maintenance of normal $\mathrm{pH}$ and electrolyte balance and interpret the Arterial Blood Gas (ABG) Analysis in various disorders.

- Be able to describe processes involved in replication and repair of DNA, the transcription and translation mechanisms, regulation of gene expression and application of various molecular biology techniques in diagnosis of diseases.

- Be able to describe the cell-mediated and humoral components of immune system and concept of antigenantibody reactions as basis for ELISA.

- Be able to describe the various tumor markers and biochemical basis of cancer therapy.

- Be able to perform and interpret biochemical analysis of urine \& CSF.

These and other skills have been defined in the proposed curriculum under CBME. ${ }^{5}$ The chief new additions to the overall programme are integration, Early Clinical Exposure (ECE), self-directed learning and special training of ethics and communication.

A noteworthy shift proposed under CBME is that of integration. Vertical integration of basic science with clinical science would ensure learning of topics with holistic approach. For instance, iron metabolism is taught as a topic in biochemistry to the students. If we integrate teaching this topic to a case of anemia in medicine along with correlation of lab investigations, it will consolidate the overall learning in a meaningful way shifting the focus from abstract information gathering to clinically relevant application.

The change in teaching-learning methods concentrating on student-centered approach would enable learning in form of 'problem solving' rather than 'information gathering'. ${ }^{6}$ This will help in building up the medical students as active learners right from inception. The traditional didactic lectures have their own relevance and should not be scratched off completely, however, their frequency should be decreased in the curriculum and they should be complimented along with case-discussions and casescenario based studies. This will also help to grip the interest of students and to delineate importance of biochemistry in understanding the basis of various disease processes. For instance, topic on "membrane-structure and function relationship" can be taught with the help of a clinical case on diarrhea. This would not only make the students inquisitive to learn but also make them understand the relevance of 
the topic as to why they should learn about membrane structure. Interactive methods should be employed for large group teaching such as brain storming, buzz session, think-pair-share, flipped classroom, etc. Problem Based Learning ( $P B L$ ) should be included as it promotes selfdirected learning by medical students. It encourages critical thinking and motivates self-learning for unknown facts.

Early Clinical Exposure (ECE) advocated in CBME is another step to rationally link theory of basic science to clinical practice and bridge the gap between these disciplines. ECE is a teaching and learning methodology that emphasizes on exposure of medical students to patients (authentic human contact) in a social or clinical setting as early as in first year of medical college for enhancement of learning of health, disease and role of health professional. ${ }^{7}$ It can be implemented in three basic forms-Firstly, 'classroom setting' wherein patient can be brought to the classroom or paper cases can be discussed. Secondly, 'hospital setting' including ward or clinic visits. Thirdly, 'community setting' that may include primary health center or community visits. ECE in community setting would attribute a societal perspective and understanding of health needs for a given population. ECE would also enable a vertical integration in the curriculum. In first year of MBBS, ECE can be implemented in any of the mentioned forms in context of biochemistry. ECE in biochemistry should also include interpretation of various lab reports in background of clinical cases. This would enable a better understanding of clinical importance of various biochemical analytes, hormone assays and enzyme markers.

CBME also emphasizes learning of ethics and communication skills in undergraduate curriculum. Imbibing of soft skills pertaining to attitude, ethics and communication during the MBBS curriculum would enable the graduates to fulfill all the roles of IMG effectively. ${ }^{8} \mathrm{MCI}$ has proposed a structured longitudinal programme known as AETCOM to be implemented with CBME. ${ }^{5}$ This aims to instill compassion in a medical graduate as a professional and enable him to discharge his duties towards the society with empathy.

\section{Conclusion}

Competency based medical education has the potential to realign medical education to meet the societal expectations effectively. At the same time it is pertinent to consider the challenges shadowing its implementation. CBME is a relatively recent concept in India and given the comfort of medical educators to the already existing system, a universal acceptance towards the change is the foremost step to its implementation. It will take few years to visualize successful incorporation of this change in the medical curriculum.

\section{References}

1. Ferguson PC, Caverzagie KJ, Nousiainen MT, Snell L et al. Changing the culture of medical training: An important step toward the implementation of competency-based medical education. Med Teach 2017; 39(6): 599-602. Available from: http://elib.vums.ac.ir/bitstream/ Hannan/21182/1/2017\%20MT\%20Volume\%2039\%20 Issue\%206\%20June\%20\%2828\%29.pdf [PubMed/ Google Scholar].

2. Frank JR, Snell L, Englander R, Holmboe ES et al. Implementing competency-based medical education: Moving forward. Med Teach 2017; 39(6): 568-573. Available from: http://elib.vums.ac.ir/bitstream/ Hannan/21176/1/2017\%20MT\%20Volume\%2039\%20 Issue\%206\%20June\%20\%286\%29.pdf [PubMed/ Google Scholar].

3. Shah N, Desai C, Jorwekar G et al. Competency-based medical education: An overview and application in pharmacology. Indian J Pharmacol 2016; 48(Suppl 1): S5-9. Available from: http://www.ijp-online.com/ article.asp?issn=0253-7613; year $=2016$; volume $=48$;iss ue=7; spage=5; epage=9; aulast=Shah $[$ PubMed $/$ Google Scholar].

4. Kumar S, Jena L, Vagha J. Need assessment of enhancing the weightage of applied biochemistry in the undergraduate curriculum at MGIMS, Sevagram. Biochem Mol Biol Educ Bimon Publ Int Union Biochem Mol Biol 2016; 44(3): 230-240. Available from: https:// iubmb.onlinelibrary.wiley.com/doi/pdf/10.1002/ bmb.20934 [PubMed/ Google Scholar].

5. UG Curriculum | MCI India. [Internet]. [cited 2019 Jul 11]. Available from: https://www.mciindia.org/CMS/ information -desk/for-colleges/ug-curriculum

6. Schwinn DA, Cooper CS, Robillard JE. Putting students at the center: moving beyond time-variable one-sizefits-all medical education to true individualization. Adv Med Educ Pract 2019; 10: 109-112. [PubMed/ Google Scholar].

7. Verma M. Early clinical exposure: New paradigm in Medical and Dental Education. Contemp Clin Dent 2016; 7(3): 287-288. Available from: http://www. contempclindent.org/article.asp?issn=0976-237X;ye ar=2016; olume=7; issue=3; spage=287; epage =288; ulast=Verma [PubMed/ Google Scholar].

8. Mitra J, Saha I. Attitude and communication module in medical curriculum: Rationality and challenges. Indian $J$ Public Health 2016; 60(2): 95-98. Available from: http://www.ijph.in/article.asp?issn=0019-557X;year =2016; volume=60; issue=2; spage=95; epage=98; aula st=Mitra [PubMed/ Google Scholar].

\section{Conflict of Interest: None}

